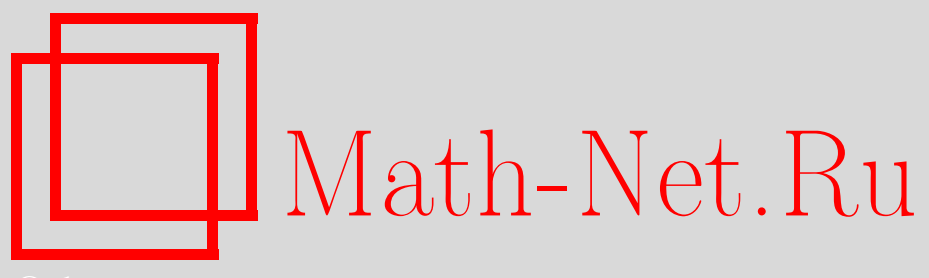

Л. Д. Беклемишев, А. В. Васильев, Е. П. Вдовин, С. С. Гончаров, В. В. Козлов, П. С. Колесников, В. Д. Мазуров, Ю. В. Матиясевич, А. С. Морозов, А. Н. Паршин, В. Г. Пузаренко, М. В. Швидефски, Юрий Леонидович Ершов (к восьмидесятилетию со дня рождения), УМН, 2020, том 75, выпуск 3, 191-194

DOI: https://doi.org/10.4213/rm9950

Использование Общероссийского математического портала Math-Net.Ru подразумевает, что вы прочитали и согласны с пользовательским соглашением http://www.mathnet.ru/rus/agreement

Параметры загрузки:

IP: 54.237 .206 .68

26 апреля 2023 г., $17: 49: 24$

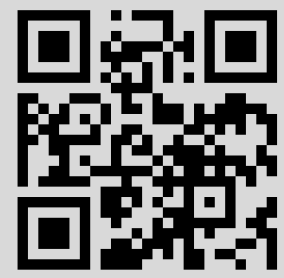




\section{Юрий Леонидович Ершов \\ (к восьмидесятилетию со дня рождения)}

1 мая 2020 г. исполнилось восемьдесят лет академику РАН Юрию Леонидовичу Ершову, выдающемуся российскому математику, известному специалисту в области алгебры, математической логики и теории алгоритмов.

Полученные им основополагающие результаты решили целый ряд известных проблем в указанных областях, внесли решающий вклад в становление этих областей, дали мощный импульс для их развития. Эти результаты, не вмещающиеся в узкоспециализированные рамки, имеют приложения в таких областях знаний, как теоретическая информатика и философия науки. Юрием Леонидовичем Ершовым опубликовано свыше 300 научных работ, среди них 13 монографий, 6 из которых переведены на иностранные языки. Юрий Леонидович является лауреатом премии РАН им. А. И. Мальцева (1992 г.), Государствен-

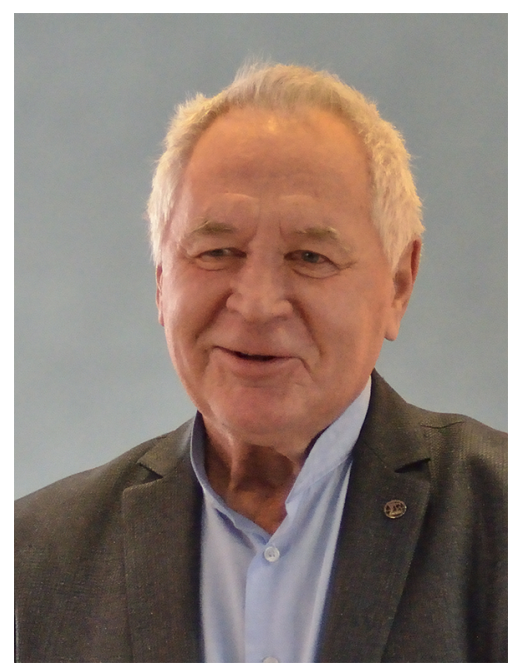
ной премии Российской Федерации в области науки и техники (2002 г.), премии Фонда им. М. А. Лаврентьева (2007 г.), премии Правительства Российской Федерации в области образования (2010 г.), Демидовской премии (2013 г.). Он награжден орденом Трудового Красного Знамени (1975 г.), орденом "Знак Почета" (1981 г.), а также орденами "За заслуги перед Отечеством" III и IV степеней (2010, 2000 гг.). В 2018 г. ему присвоено звание "Почетный житель города Новосибирска".

По признанию самого Юрия Леонидовича, большое влияние на становление его как математика оказал его научный руководитель академик Анатолий Иванович Мальцев, основатель сибирской школы алгебры и математической логики. Под его руководством еще в студенческие годы Юрий Леонидович получил свои первые научные результаты и уже через несколько месяцев после окончания Новосибирского государственного университета в 1964 г. защитил кандидатскую диссертацию, а всего через два года, в 1966 г., - докторскую. Вошедшие в докторскую диссертацию результаты о разрешимости элементарных теорий полей были охарактеризованы специалистами как выдающиеся достижения в бурно развивающейся на тот момент области математики, связанной с алгоритмическими аспектами элементарных свойств классических алгебраических систем.

Еще будучи студентом Новосибирского государственного университета, Юрий Леонидович нашел решение известной проблемы Тарского о разрешимости элементарной теории поля $p$-адических чисел, а чуть позднее разработал новые мощные методы доказательства разрешимости и неразрешимости элементарных теорий. Эти методы, ставшие к настоящему времени классическими, оказались настолько эффективными,

DOI: https://doi.org/10.4213/rm9950 
что позволили получить ответы на вопросы о разрешимости элементарной теории для целого ряда алгебраических систем, играющих ключевую роль в алгебре. Эти достижения совсем молодого ученого продемонстрировали его яркий математический талант и быстро принесли ему мировую известность. Однако изучение этих интересных и трудных вопросов на этом не завершилось, и к этой тематике Юрий Леонидович возвращался еще не раз в своих работах. Уже в новом веке Юрием Леонидовичем были проведены глубокие исследования и получены впечатляющие результаты в теории полей и многочленов. Одним из самых ярких достижений является конструкция разрешимого поля, удивительного расширения поля действительных чисел и поля p-адических чисел. Юрием Леонидовичем была развита глубокая теория кратно нормированных полей, которая нашла отражение в одноименной монографии, вышедшей в свет в 2000 г. на русском и английском языках и удостоенной Государственной премии Российской Федерации в области науки и техники.

С именем Юрия Леонидовича тесно связано изучение дистрибутивных решеток с относительными дополнениями (известных как алгебры Ершова), булевых алгебр и проконечных групп, где им и другими представителями сибирской школы алгебры и логики получены глубокие результаты, а характеристики Ершова-Кетонена и Ершова-Тарского активно используются математиками во всем мире. Юрием Леонидовичем разработаны методы построения вычислимых систем как алгебраических замыканий и скулемовских обогащений, известные как теорема о ядре и метод с конечными препятствиями. Изучение алгоритмических аспектов алгебраических систем привело к возникновению общего понятия конструктивной алгебраической системы и понятия нумерации. Юрием Леонидовичем создана и развита общая теория нумераций, связанная с изучением проблем существования универсальных представлений и мер сложности различных абстрактных представлений систем. При изучении свойств вычислимых нумераций конечных множеств им введена разностная иерархия множеств натуральных чисел, известная сейчас как иерархия Ершова, найдена характеризация решетки $m$-степеней. Эти результаты, также получившие широкую известность, нашли отражение в его монографии “Теория нумераций", опубликованной в 1977 г., и отмечены премией им. А. И. Мальцева Российской академии наук. Решающий вклад внес Юрий Леонидович в развитие теории конструктивных моделей. K фундаментальным проблемам этой области математики, изучающей смежные вопросы теории моделей и теории алгоритмов, основы которой заложены в работах Анатолия Ивановича Мальцева, относятся проблемы существования конструктивных моделей для конкретных элементарных теорий, а также существование алгоритмических представлений для абстрактных систем. Полученные Юрием Леонидовичем результаты в этом направлении вошли в его монографию "Проблемы разрешимости и конструктивные модели", изданную в 1980 г. Дальнейшее развитие теории конструктивных моделей нашло отражение в монографии "Конструктивные модели", написанной Юрием Леонидовичем в соавторстве с Сергеем Савостьяновичем Гончаровым и вышедшей в свет в 1999 г. Основополагающие результаты получены Юрием Леонидовичем и в теории допустимых множеств, на основе которой им были построены теория вычислимости в допустимых надстройках над абстрактными системами, а также теория вычислимых отношений конечных типов. Эти результаты позволили взглянуть на разные разделы математической логики с единой точки зрения, прояснили суть некоторых математических понятий, а также связали воедино понятия определимости и вычислимости. Эти результаты нашли свое применение в новом подходе к созданию языков программирования, так называемом семантическом программировании, характерной чертой которого является взгляд на вычислимость не через алгоритмическую реализацию, а через определимость в формальном языке, допускающем ясную семантику. Собственный подход к теории допустимых множеств, теория $\Sigma$-выражений и динамическая логика над допустимыми множествами были изложены 
Юрием Леонидовичем в его монографии "Определимость и вычислимость", которая опубликована на русском и английском языках в 1996 г. и переиздана с исправлениями и дополнениями в 2000 г. В 1998 г. во всемирно известной серии "Studies in logic and the foundations of mathematics" вышло двухтомное издание "Handbook of recursive mathematics", созданное под редакцией Ю.Л. Ершова и С. С. Гончарова совместно с американскими коллегами В. Мареком, А. Нероудом и Дж. Реммелем. Завершившее большой международный проект по изложению основных идей, методов и достижений этого актуального направления исследований, в работе над которым приняли участие ведущие специалисты в данной области, это издание сыграло и продолжает играть важную роль в развитии теории алгоритмов и рекурсивной математики.

Полученные Юрием Леонидовичем фундаментальные результаты о непрерывных и вычислимых функционалах конечных типов привели его в дальнейшем к построению глубокой теории нехаусдорфовых топологических пространств с аппроксимациями, известных в настоящее время как пространства Ершова. Одновременно и с использованием другого подхода эти вопросы рассматривались американским математиком Даной Скоттом. Основополагающим для подхода Скотта является частичный порядок, заданный на множестве. В отличие от этого, в теории аппроксимационных пространств, развитой Юрием Леонидовичем, ключевую роль играет топология на множестве, в соответствии с которой определяется частичный порядок. Этот более общий подход, изложенный в его монографии "Топология для дискретной математики", выходящей в свет в 2020 г., позволил развить глубокую и стройную теорию, которая впоследствии послужила базисом для создания бестипового $\lambda$-исчисления и теории денотационных семантик.

Следует отметить также труды Ю.Л. Ершова, посвященные философии и методологии математики. Написанное им в соавторстве с С. С. Гончаровым и К. Ф. Самохваловым учебное пособие "Введение в логику и методологию науки" было отмечено премией Государственного комитета Российской Федерации по высшему образованию, а цикл его трудов "Концепция формирования логико-математического образования в высшей школе" в 2010 г. был удостоен премии Правительства Российской Федерации в области образования. Написанный Ю. Л. Ершовым совместно с Е. А. Палютиным и ставший к настоящему времени классическим учебник "Математическая логика" выдержал несколько изданий в России и за рубежом и воспитал много поколений студентов-математиков.

Не только исключительная глубина проникновения в суть исследуемых сложных вопросов, но и выбор наиболее естественного языка для их изучения является характерным для работ Юрия Леонидовича. Впечатляет также и широта его научного кругозора, способность взглянуть на проблему нестандартным образом и найти порой неожиданные взаимосвязи между различными понятиями. Его научные труды, а также лекции и доклады отличает исключительная ясность и естественность, тем не менее никогда не идущая в ущерб математической строгости и корректности изложения. В подтверждение его основного принципа "математика едина", в его работах тесно переплетаются методы из различных областей, а полученные с их применением результаты фундаментальны и имеют весьма широкий спектр приложений. Написанные Юрием Леонидовичем монографии, а также его доклады и лекции не только служат великолепным введением в изучаемые им научные области, но и намечают направления для их дальнейшего развития. Юрий Леонидович щедро делится с коллегами и учениками своими неиссякаемыми идеями. Своей увлеченностью и энтузиазмом в изучении сложнейших математических вопросов, красотой полученных им результатов он сделал математику притягательной для многих поколений начинающих исследователей: его учениками защищено 15 докторских и более 40 кандидатских диссертаций. Юрий Леонидович является в течение десятилетий признанным лидером сибирской школы алгебры и математической логики, основанной Анатолием 
Ивановичем Мальцевым и известной далеко за пределами России. Из этой школы вышли более 40 докторов наук и свыше 100 кандидатов наук, работающих в Институте математики им. С. Л. Соболева Сибирского отделения РАН, Новосибирском государственном университете, а также в научных и образовательных учреждениях России и других стран.

Юрий Леонидович вносит огромный вклад в развитие и процветание этой уникальной школы не только своими блестящими научными результатами. Много усилий он отдал также педагогической и научно-организационной работе. В течение нескольких десятков лет Юрий Леонидович заведовал кафедрой алгебры и математической логики Новосибирского государственного университета, с 1973 по 1976 г. был деканом механико-математического факультета НГУ, а с 1985 по 1993 г. - ректором НГУ. С 2002 по 2011 г. он занимал пост директора Института математики им. С. Л. Соболева СО РАН. При его непосредственном участии физико-математическая школа, созданная академиком Михаилом Алексеевичем Лаврентьевым, была преобразована в Специализированный учебно-научный центр при Новосибирском государственном университете. Он стал одним из основателей и первым руководителем Научно-исследовательского института математико-информационных основ обучения, в 1998 г. преобразованного в Институт дискретной математики и информатики. Юрий Леонидович является главным редактором "Сибирского математического журнала" и журнала "Алгебра и логика". Он руководит одноименным семинаром и является председателем программного комитета международной конференции "Мальцевские чтения", которая проводится в Новосибирске ежегодно начиная с 1998 г. Юрий Леонидович является председателем Объединенного ученого совета по математике и информатике Сибирского отделения РАН, председателем Экспертного совета по информатике при представителе Президента в Сибирском федеральном округе, президентом Сибирского фонда алгебры и логики, председателем Фонда поддержки ММФ НГУ.

Описание высочайших профессиональных достижений Юрия Леонидовича было бы однобоким без упоминания его человеческих качеств. Его отличают прямота и высокая требовательность к себе и окружающим в сочетании с поразительной трудоспособностью и упорством. В общении с окружающими Юрия Леонидовича характеризуют внимательность, доброжелательность и искреннее уважение к людям.

Дорогой Юрий Леонидович! От имени Ваших учеников, коллег, а также многочисленных членов сибирской школы алгебры и логики мы от всей души поздравляем Вас с замечательным юбилеем и желаем Вам здоровья, счастья, благополучия для Вас и Ваших близких и осуществления всех Ваших творческих замыслов!

Л.Д. Беклемишев, А.В. Васильев, Е.П. Вдовин, С. С. Гончаров, В.В. Козлов, П.С. Колесников, В.Д. Мазуров, Ю.В. Матиясевич, А.С. Морозов, А.Н. Паршин, В.Г. Пузаренко, М.В. Швидефски 